\title{
IMPLEMENTASI ALGORITMA DIJKSTRA UNTUK MENENTUKAN JALUR TERPENDEK DALAM DISTRIBUSI BARANG
}

\author{
Ikhsan Baharudin ${ }^{* 1}$, Ahmad Jaka Purwanto 2 , Teguh Rahayu Budiman ${ }^{3}$, Muchammad Fauzi ${ }^{4}$ \\ 1,2,3,4Program Studi Teknik Industri, Universitas Widyatama Bandung \\ ikhsan.baharudin@widyatama.ac.id ${ }^{* 1}$, ahmad.jaka@widyatama.ac.id ${ }^{2}$, \\ teguh.budiman@widyatama.ac.id ${ }^{3}$, muchammad.fauzi@widyatama.ac.id ${ }^{4}$
}

\begin{abstract}
PT. X is a company domiciled in Gedebage, Bandung which is engaged in the manufacturing industry by producing precision parts using CNC machines. PT. X is a sub-contracting company that usually serves project work from other companies. PT. $Y$ and PT. $Z$ is a regular customer who often works with PT. X. So that PT. X often sends finished products directly to PT. Y who is domiciled on Jl. Gatot Subroto, Bandung and also PT. $Z$ who is domiciled on Jl. Pajajaran, Bandung. To minimize the cost of distribution of goods, PT. X must determine an adequate path taking into account the optimization of transportation costs. One of the variables that affect transportation costs is distance. It is assumed that the optimal path for transportation costs is the shortest distance using the Dijkstra method. This test uses data from Google Maps to find out the distance to each destination, making it easier to get the shortest path. Obtained the shortest path from PT. X to PT.Y is $12.3 \mathrm{Km}$ via West Java Police then Carefour, while the shortest route is from PT. Y to PT. Z is 10.7 Km via Simpang Lima then Vie Hotel Westhoff. So that the optimal total mileage for distributing goods is $23 \mathrm{Km}$.
\end{abstract}

Keywords: Dijkstra, Transport, Stochastic, Operations Research, Shortest Path.

\begin{abstract}
Abstrak
PT. X merupakan sebuah perusahaan yang berdomisili di Gedebage, Bandung yang bergerak di industri manufaktur dengan memproduksi part-part presisi dengan menggunakan mesin CNC. PT. X adalah perusahaan sub-kontraktor yang biasa melayani pekerjaan proyekan dari perusahaan lain. PT. Y dan PT. Z merupakan pelanggan tetap yang sering bekerja sama dengan PT. X. Sehingga PT. X sering mengirimkan produk jadi langsung kepada PT. Y yang berdomisili di Jl. Gatot Subroto, Bandung dan juga PT. Z yang berdomisili di Jl. Pajajaran, Bandung. Untuk meminimalisir ongkos distribusi barang, PT. $X$ harus menentukan jalur yang memadai dengan mempertimbangkan optimalisasi ongkos transportasi. Variabel yang mempengaruhi ongkos transportasi salah satunya adalah jarak. Diasumsikan bahwa jalur yang optimal untuk biaya transportasi adalah jarak yang terpendek dengan menggunakan metode Dijkstra. Pengujian ini menggunakan data dari Google Maps untuk mengetahui jarak pada setiap lokasi yang dituju sehingga memudahkan dalam mendapatkan jalur terpendek. Didapatkan jalur terpendek dari PT. X ke PT.Y adalah 12,3 Km dengan melalui Polda Jawa Barat kemudian Carefour, sementara jalur terpendek dari PT. Y ke PT. Z adalah 10,7 Km dengan melalui Simpang Lima kemudian Vie Hotel Westhoff. Sehingga total jarak tempuh yang optimal untuk mendistribusikan barang adalah $23 \mathrm{Km}$.
\end{abstract}

Kata kunci: Dijkstra, Transportasi, Stokastik, Riset Operasi, Jalur Terpendek. 
Jurnal Lebesgue : Jurnal Ilmiah Pendidikan Matematika, Matematika dan Statistika

Ikhsan Baharudin, Ahmad Jaka Purwanto, Teguh Rahayu Budiman, Muchammad Fauzi

Volume 2, No. 2, Agustus 2021 hal.194-203

DOI Artikel : $10.46306 / 1 b . v 2 i 2.74$

\section{PENDAHULUAN}

Diera sekarang banyak perusahaan yang menggunakan jasa sub-kontraktor untuk memenuhi permintaan atau target produksinya. Sub-kontraktor adalah sebuah pihak yang ikut dalam pelaksana proyek dibawah kendali main-kontraktor (Ismet, 2014). Banyak perusahaan menggunakan jasa sub-kontraktor dikarenakan kapasitas mesin yang tidak memadai atau target produksi yang banyak dengan sumber daya yang tidak mencukupi. PT. X merupakan sebuah perusahaan yang berdomisili di Gedebage, Bandung yang bergerak di industri manufaktur dengan memproduksi part-part presisi dengan menggunakan mesin CNC. PT. X adalah perusahaan sub-kontraktor yang biasa melayani pekerjaan proyekan dari perusahaan lain. PT. $\mathrm{X}$ yang memiliki berbagai jenis mesin $C N C$ baik itu CNC Milling, CNC Turning, CNC Turning Milling, Sincom hingga EDM serta memiliki beberapa peralatan ukur yang memadai mampu menarik beberapa perusahaan besar untuk bekerjasama. PT. Y dan PT. Z merupakan dua perusahaan besar di daerah Bandung yang menjadi pelanggan tetap dari PT. X sehingga sering bekerja sama dengan PT. X. Dalam pekerjaan sub-kontraktor, sering kali material di adakan oleh perusahaan sub-kontraktor, namun tidak jarang juga para main-kontraktor yang menyediakan material sehingga perusahaan sub-kontraktor hanya ikut andil dalam proses pembuatan barang saja.

PT. X memiliki departemen pengiriman sendiri untuk mengirimkan barang-barang jadi kepada customer main-kontraktor daerah lokal. Oleh karena itu, PT. X sering mengirimkan produk jadi langsung kepada PT. Y yang berdomisili di Jl. Gatot Subroto, Bandung dan juga PT. Z yang berdomisili di Jl. Pajajaran, Bandung. Ongkos distribusi merupakan sebuah variabel biaya yang tidak termasuk kedalam harga produk dari PT. X. Jadi, semakin besar biaya yang dikeluarkan untuk ongkos distribusi maka semakin kecil keuntungan yang akan didapatkan oleh PT. X. Untuk meminimalisir ongkos distribusi barang, PT. X harus menentukan jalur yang memadai dengan mempertimbangkan optimalisasi biaya transportasi. Variabel yang mempengaruhi ongkos transportasi salah satunya adalah jarak. Jarak yang terpendek akan mengoptimalkan biaya distribusi (Harahap \& Khairina, 2017). Selain itu, dengan menggunakan jalur terpendek maka proses pengiriman akan lebih cepat sehingga bagian distribusi bisa mengirimkan barang ke lebih banyak tempat dalam satu hari.

Proses penghitungan jalur terpendek merupakan proses mencari jarak terpendek atau biaya terkecil suatu jalur dari node awal ke node tujuan dalam sebuah jaringan. Pencarian jalur terpendek atau yang disebut shortest path problem merupakan salah satu permasalahan yang menarik untuk dianalisa. Shortest path problem adalah sebuah masalah dalam mencari jalan 
Jurnal Lebesgue : Jurnal Ilmiah Pendidikan Matematika, Matematika dan Statistika

Ikhsan Baharudin, Ahmad Jaka Purwanto, Teguh Rahayu Budiman, Muchammad Fauzi

Volume 2, No. 2, Agustus 2021 hal.194-203

DOI Artikel : 10.46306/lb.v2i2.74

diantara 2 titik atau simpul dengan menggunakan bobot yang minimal dari titik asal menuju titik tujuan (Halda et al., 2016). Pencarian rute terpendek ini telah diterapkan di berbagai bidang untuk mengoptimasi kinerja sebuah sistem, baik untuk meminimalkan ongkos atau mempercepat jalannya suatu proses. Dalam melakukan pencarian jalur diperlukan sebuah algortima, algoritma didefinisikan sebagai urutan langkah-langkah logis dan sistematis dalam mencari suatu solusi dari suatu permasalahan yang ada. Langkah-langkah dalam memecahkan masalah bisa dilakukan dalam berbagai cara dengan karakteristik yang berbeda-beda dari masing-masing langkah. Setiap algoritma tersebut memiliki cara kerja yang berbeda-beda dalam menentukan solusi yang paling optimal. Pengoptimalan atau optimasi sangat berguna di hampir segala bidang terutama bidang induatri dalam rangka melakukan usaha secara efektif dan efisien untuk mencapai target hasil yang ingin dicapai. Tentunya hal ini akan sangat sesuai dengan prinsip ekonomi yang berorientasikan untuk senantiasa menekan pengeluaran untuk menghasilkan outputan yang maksimal (Kholik et al., 2018). Optimasi ini juga penting karena persaingan saat ini dapat dikatakan sangat ketat.

Salah satu metode optimasi yang tepat dalam penentuan jalur transportasi terpendek adalah dengan menggunakan algoritma Dijkstra. Algoritma Dijkstra diberi nama yang sesuai dengan nama penemunya yaitu seorang ilmuwan berkebangsaan Belanda yang bernama Edsger Dijkstra (Wijayanti et al., 2015). Algoritma Dijkstra merupakan sebuah algoritma greedy yang dipakai dalam memecahkan permasalahan jarak terpendek untuk sebuah graf berarah dengan bobot-bobot sisi (edge) yang bernilai tak negatif. Ide dasar algoritma Dijkstra sendiri adalah pencarian nilai cost yang terdekat dengan tujuan yang berfungsi pada sebuah graf berbobot, sehingga bisa membantu memberikan pilihan jalur. Tujuan algoritma ini untuk menemukan jalur terpendek berdasarkan bobot terkecil dari satu titik ke titik lainnya (Ardana \& Saputra, 2016). Dalam iterasinya, algoritma Dijkstra akan mencari satu titik yang jumlah bobotnya dari titik 1 terkecil. Titik-titik yang terpilih dipisahkan, dan titik-titik tersebut tidak diperhatikan lagi dalam iterasi berikutnya (Agustinus, 2018).

\section{METODE PENELITIAN}

Metode penelitian merupakan langkah yang dilakukan oleh peneliti dalam rangka untuk mengumpulkan informasi atau data serta melakukan investigasi pada data tersebut. Flowchart langkah penelitian ditunjukkan pada gambar 1 di bawah ini. 


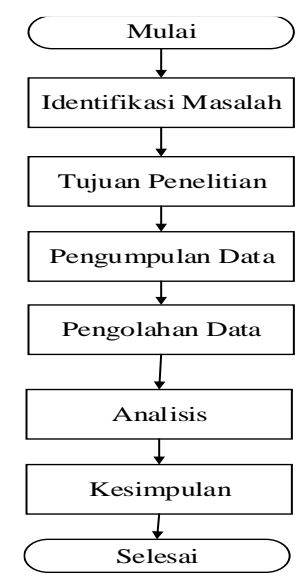

Gambar 1. Flowchart Metode Penelitian

Setelah mengidentifikasi masalah distribusi barang pada PT. X dan menetapkan tujuan untuk memperoleh jalur terpendek untuk menuju PT. Y dan PT. Z selanjutnya dilakukan pengumpulan data. Pengumpulan data pada penelitian ini menggunakan jenis data kuantitatif dan kualitatif. Data kuantitatif didapatkan dari Google Maps untuk mengetahui jalur dan jarak antar node dari PT. X ke PT. Y hingga PT. Z dengan satuan ukuran kilometer (Km), penentuan point-point ini adalah dengan menentukan setiap titik pertemuan yang mungkin terjadi di setiap jalur seperti persimpanagan, perempatan atau pertigaan. Sementara data kualitatif diperoleh dari perusahaan yaitu PT. X dalam bentuk informasi baik secara lisan maupun tulisan, dalam hal ini informasi terkait perusahaan main kontraktor yang sudah sering melakukan kerjasama.

Pengolahan data menggunakan algoritma Dijkstra untuk menentukan jalur terpendek dalam melakukan proses distribusi barang. Cara kerja algoritma Dijkstra menggunakan strategi greedy, dimana pada setiap langkah dipilih sisi dengan bobot terkecil yang menghubungkan sebuah simpul lain yang belum terpilih (Nurrizky et al., 2020). Gambar 2 berikut ini merupakan contoh node dari titik origin menuju destination.

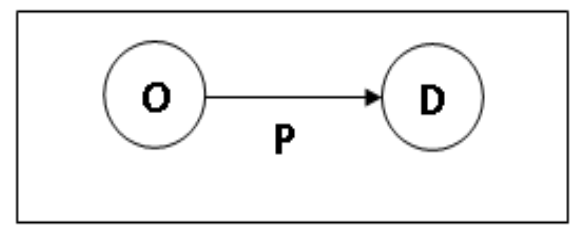

Gambar 2. Origin ke destination

Logika pada algoritma Dijkstra ialah sebagai berikut (Ferdiansyah \& Rizal, 2013):

1) Tetapkan nilai jarak pada setiap simpul. Tetapkan 0 untuk simpul awal dan tak terbatas pada semua simpul yang lain.

2) Tandai semua simpul sebagai belum dikunjungi, tetapkan simpul sekarang sebagai simpul awal. 
Jurnal Lebesgue : Jurnal Ilmiah Pendidikan Matematika, Matematika dan Statistika

Ikhsan Baharudin, Ahmad Jaka Purwanto, Teguh Rahayu Budiman, Muchammad Fauzi

Volume 2, No. 2, Agustus 2021 hal.194-203

DOI Artikel : 10.46306/lb.v2i2.74

3) Untuk simpul sekarang, anggap semua tetangga yang belum dikunjungi dan hitung jarak terhadap simpul sekarang. Jika jarak sekarang lebih kecil dari jarak yang sebelumnya direkam, timpa nilainya.

4) Ketika kita selesai menghitung tetangga dari simpul sekarang, tandai sebagai telah dikunjungi. Jaraknya disimpan dan dinyatakan minimal.

5) Jika semua simpul telah dikunjungi, nyatakan sebagai selesai. Jika tidak, nyatakan simpul yang belum dikunjungi dengan jarak terkecil sebagai simpul sekarang dan ulangi langkah 3.

Tahap analisis dilakukan setelah melakukan pengolahan data. Hasil analisis digunakan untuk menentukan tindakan lanjutan sebagai petunjuk untuk langkah penelitian selanjutnya.

Kemudian, tahap kesimpulan merupakan bagian akhir dari sebuah penelitian yang menyajikan tentang gambaran dari hasil penelitian tersebut.

\section{HASIL DAN PEMBAHASAN}

Langkah pertama dalam mencari jalur terpendek adalah dengan melakukan pemetaan awal setiap jalur distribusi dari titik origin menuju titik destination, menentukan setiap titik pertemuan yang mungkin berdasarkan peta Google Maps dan memberikan node beserta keterangannya. Pemberian node dapat dilihat dari tabel 1 dibawah ini.

Tabel 1. Origin, Jalur Distribusi dan Destination

\begin{tabular}{ccc}
\hline Node & Lokasi & Keterangan \\
\hline $\mathrm{X}$ & PT. X & Origin \\
\hline A & Polda Jawa Barat & Jalur Distribusi \\
\hline B & Bunderan Cibiru & Jalur Distribusi \\
\hline C & Carefour & Jalur Distribusi \\
\hline D & Kiara Arta Park & Jalur Distribusi \\
\hline Y & PT. Y & Destination 1 \\
\hline E & Simpang Lima & Jalur Distribusi \\
\hline F & Museum Geologi & Jalur Distribusi \\
\hline G & Vie Hotel Westhoff & Jalur Distribusi \\
\hline Z & PT. Z & Destination 2
\end{tabular}

Gambar 3 dibawah ini adalah peta untuk mengetahui jarak antar node dari PT. X ke PT. Y dan PT. Z yang bersumber dari Google Maps. 
Jurnal Lebesgue : Jurnal Ilmiah Pendidikan Matematika, Matematika dan Statistika

Ikhsan Baharudin, Ahmad Jaka Purwanto, Teguh Rahayu Budiman, Muchammad Fauzi

Volume 2, No. 2, Agustus 2021 hal.194-203

DOI Artikel : 10.46306/lb.v2i2.74

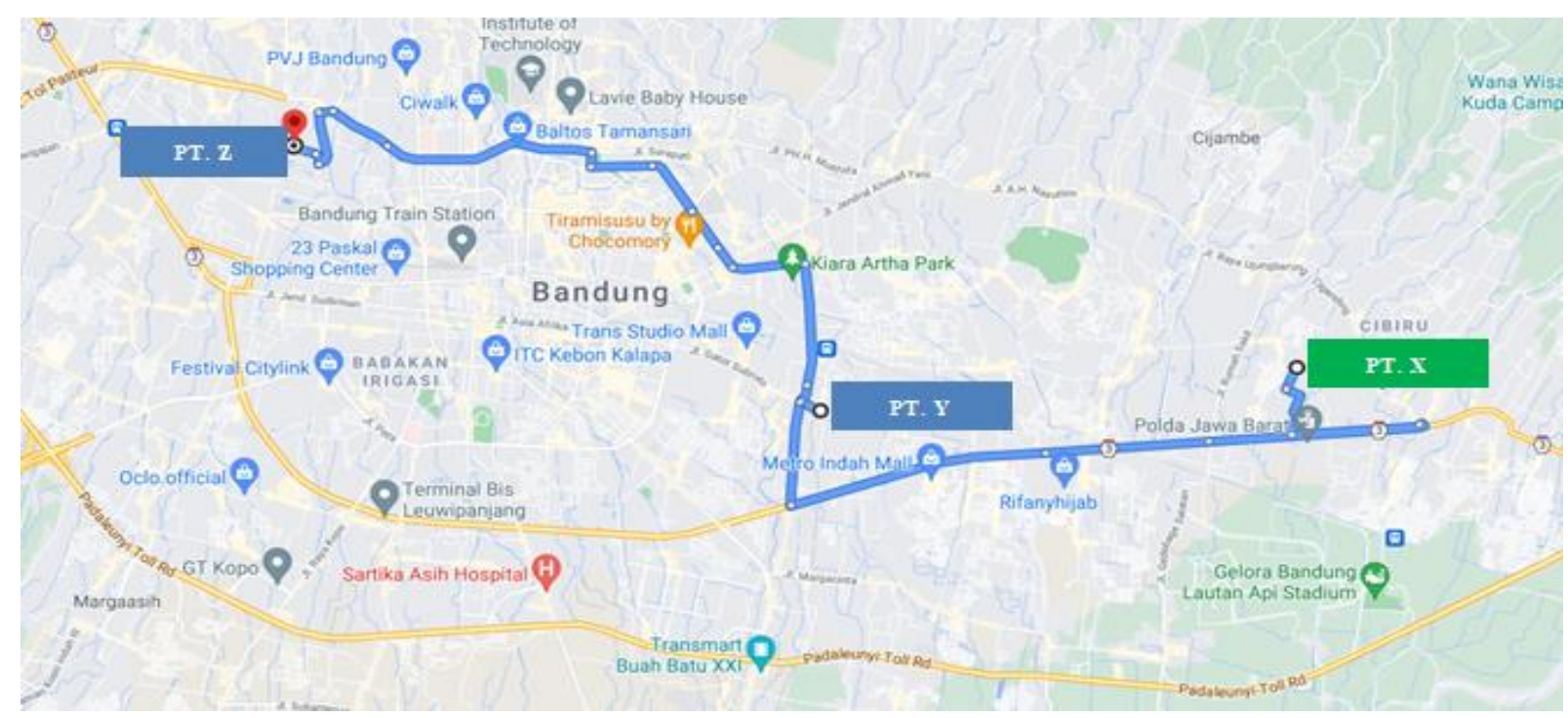

Gambar 3. Peta Google Maps dari PT. X ke PT. Y dan PT. Z

Google Maps merupakan jasa peta gratis dan online yang disediakan oleh Google. Google Maps dapat ditemukan di alamat web http://maps.google.com. Pada situs tersebut dapat melihat informasi geografis pada hampir semua wilayah di muka bumi (Mahdia, 2013). Layanan ini interaktif, karena di dalam peta dapat digeser sesuai keinginan pengguna, mengubah tingkat zoom, dan mengubah tampilan pada peta. Google Maps juga menawarkan peta yang dapat diseret dan gambar satelit untuk seluruh dunia, serta dapat mengetahui jarak antar titik lokasi yang akan dimanfaatkan oleh peneliti untuk mencari jalur rekomendasi yang optimal pada distribusi barang dengan algoritma Dijkstra. Tabel 2 berikut adalah ringkasan jarak antar node.

Tabel 2. Ringkasan jarak antar node

\begin{tabular}{llc}
\hline \multicolumn{1}{c}{ Dari } & \multicolumn{1}{c}{ Ke } & Jarak (Km) \\
\hline X (PT. X) & A (Polda Jawa Barat) & 2,7 \\
\hline X (PT. X) & B (Bunderan Cibiru) & 3,1 \\
\hline A (Polda Jawa Barat) & B (Bunderan Cibiru) & 2,8 \\
\hline A (Polda Jawa Barat) & C (Carefour) & 7,3 \\
\hline B (Bunderan Cibiru) & D (Kiara Arta Park) & 12,8 \\
\hline C (Carefour) & Y (PT. Y) & 2,3 \\
\hline C (Carefour) & E (Simpang Lima) & 5 \\
\hline Y (PT. Y) & E (Simpang Lima) & 3,4 \\
\hline Y (PT. Y) & D (Kiara Arta Park) & 2,9 \\
\hline D (Kiara Arta Park) & F (Museum Geologi) & 4,3 \\
\hline D (Kiara Arta Park) & E (Simpang Lima) & 3,8 \\
\hline
\end{tabular}


Jurnal Lebesgue : Jurnal Ilmiah Pendidikan Matematika, Matematika dan Statistika

Ikhsan Baharudin, Ahmad Jaka Purwanto, Teguh Rahayu Budiman, Muchammad Fauzi

Volume 2, No. 2, Agustus 2021 hal.194-203

DOI Artikel : 10.46306/lb.v2i2.74

\begin{tabular}{lll}
\hline E (Simpang Lima) & G (Vie Hotel Westhoff) & 4,6 \\
\hline F (Museum Geologi) & G (Vie Hotel Westhoff) & 3,5 \\
\hline G (Vie Hotel Westhoff) & Z (PT. Z) & 2,7 \\
\hline
\end{tabular}

. Pemetaan awal setiap jalur dapat dilihat seperti pada gambar 4 dibawah ini:

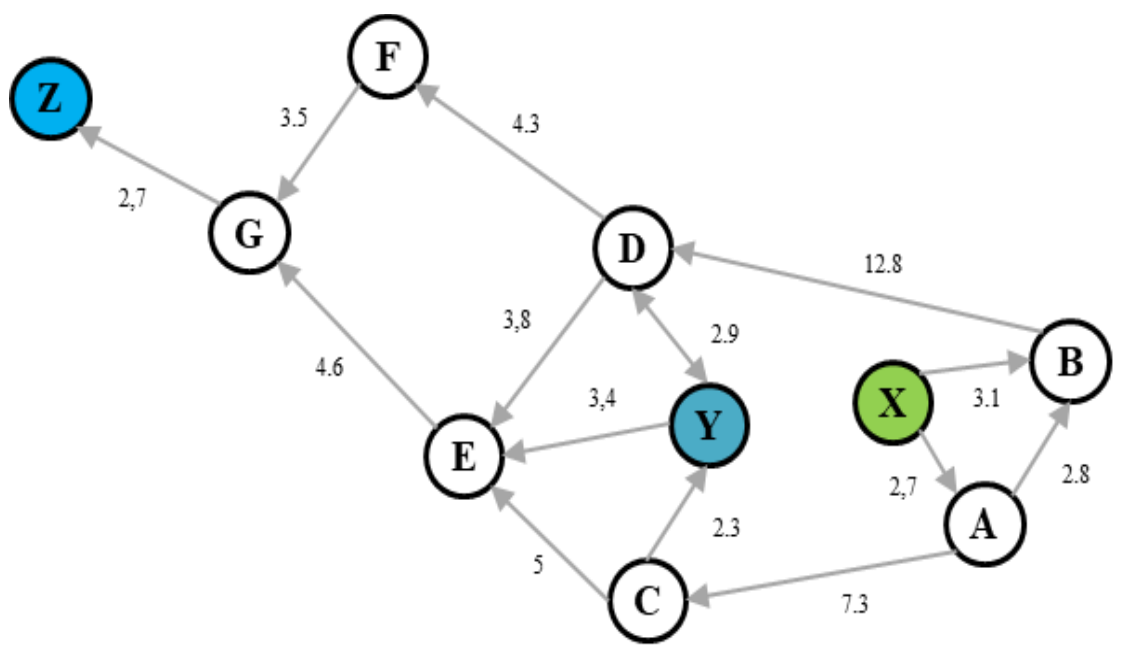

Gambar 4. Pemetaan awal jalur distribusi dari origin menuju destination.

Setelah dilakukan pemetaan awal dan jarak sudah diketahui kemudian dilanjutkan perhitungan algoritma Dijkstra untuk memperoleh jalur terpendek dari PT. X ke PT. Y. Tabel 3 menunjukan hasil perhitungan jalur terpendek dari PT. X menuju PT. Y menggunakan algoritma Dijkstra, sebagai berikut:

Tabel 3. Iterasi perhitungan algoritma Dijkstra dari PT. X ke PT. Y

\begin{tabular}{c|c|c}
\hline Iterasi & Jalur & Jarak $(\mathbf{K m})$ \\
\hline \multirow{2}{*}{ Iterasi I } & $\mathrm{X}-\mathrm{A}$ & 2,7 \\
\cline { 2 - 3 } & $\mathrm{X}-\mathrm{B}$ & 3,1 \\
\hline \multirow{2}{*}{ Iterasi II } & $\mathrm{X}-\mathrm{A}-\mathrm{C}$ & 10 \\
\cline { 2 - 3 } & $\mathrm{X}-\mathrm{B}-\mathrm{D}$ & 15,9 \\
\hline \multirow{2}{*}{ Iterasi III } & $\mathrm{X}-\mathrm{A}-\mathrm{C}-\mathrm{Y}$ & 12,3 \\
\cline { 2 - 3 } & $\mathrm{X}-\mathrm{B}-\mathrm{D}-\mathrm{Y}$ & 18,8 \\
\hline
\end{tabular}

Berdasarkan perhitungan pada tabel 3. Iteraasi I dipilih jalur terpendek dari X yaitu A, kemudian pada iterasi II didapatkan jalur terpendek yaitu dari X-A-C, sehingga dilanjutkan pemilihan jalur terpendek pada iterasi III adalah X-A-C-Y dengan total jarak 12,3 Km. Jalur yang ditempuh mulai dari: 
Jurnal Lebesgue : Jurnal Ilmiah Pendidikan Matematika, Matematika dan Statistika

Ikhsan Baharudin, Ahmad Jaka Purwanto, Teguh Rahayu Budiman, Muchammad Fauzi

Volume 2, No. 2, Agustus 2021 hal.194-203

DOI Artikel : 10.46306/lb.v2i2.74

1. PT. X

2. Polda Jawa Barat

3. Carefour

4. PT. Y

Dilakukan pembuktian menggunakan tabel matriks yang ditunjukan pada tabel 4 dibawah ini:

Tabel 4. Matriks perhitungan algoritma Dijkstra dari PT. X ke PT. Y

\begin{tabular}{c|c|c|c|c|c|c}
\hline Node & $\mathbf{X}$ & $\mathbf{A}$ & $\mathbf{B}$ & $\mathbf{C}$ & $\mathbf{D}$ & $\mathbf{Y}$ \\
\hline $\mathbf{X}$ & $0 \mathrm{X}$ & $4,7 \mathrm{X}$ & $3,1 \mathrm{X}$ & $\infty$ & $\infty$ & $\infty$ \\
\hline $\mathbf{B}$ & & $4,7 \mathrm{X}$ & $3,1 \mathrm{X}$ & $\infty$ & $15,9 \mathrm{~B}$ & $\infty$ \\
\hline $\mathbf{A}$ & & $4,7 \mathrm{X}$ & & $10 \mathrm{~A}$ & $15,9 \mathrm{~B}$ & $\infty$ \\
\hline $\mathbf{C}$ & & & & $10 \mathrm{~A}$ & $15,9 \mathrm{~B}$ & $12,3 \mathrm{C}$ \\
\hline $\mathbf{Y}$ & & & & & & $12,3 \mathrm{C}$ \\
\hline
\end{tabular}

Pemetaan jalur distribusi yang optimal dari PT. X ke PT. Y terlihat pada gambar 5 sebagai berikut:

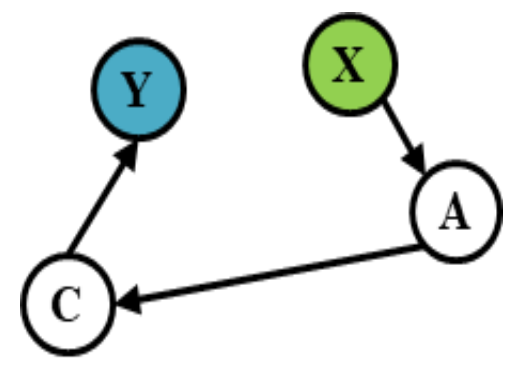

Gambar 5. Pemetaan jalur distribusi optimal dari PT. X ke PT. Y

Kemudian dilanjutkan perhitungan algoritma Dijkstra untuk memperoleh jalur terpendek pendistribusian barang dari PT. Y ke PT. Z, proses perhitungan jalur terpendek dari PT. Y menuju PT. Z ditunjukan pada tabel 5 berikut ini:

Tabel 5. Iterasi perhitungan algoritma Dijkstra dari PT. Y ke PT. Z

\begin{tabular}{c|c|c}
\hline \multicolumn{1}{c|}{ Iterasi } & Jalur & Jarak (Km) \\
\hline \multirow{2}{*}{ Iterasi I } & Y-D & 2,9 \\
\cline { 2 - 3 } & Y-E & 3,4 \\
\hline \multirow{2}{*}{ Iterasi II } & Y-D-F-G & 10,7 \\
\cline { 2 - 3 } & Y-E-G & 8 \\
\hline \multirow{2}{*}{ Iterasi III } & Y-D-F-G-Z & 13,4 \\
\cline { 2 - 3 } & Y-E-G-Z & 10,7 \\
\hline
\end{tabular}


Berdasarkan perhitungan pada tabel 5 diatas, pada iterasi I dipilih jarak terpendek yaitu dari Y ke D, pada iterasi II untuk menuju titik G dipilih titik Y ke E karena didapat jarak lebih pendek dibandingkan dari titik Y ke D, sehingga diperoleh jarak terpendek pada iterasi III adalah YE-G-Z dengan total jarak 10,7 Km. Jalur yang ditempuh mulai dari:

1. PT. Y

2. Simpang Lima

3. Vie Hotel Westhoff

4. PT.Z

Dilakukan pembuktian menggunakan tabel matriks yang ditunjukan pada tabel 6 dibawah ini:

Tabel 6. Matriks perhitungan algoritma Dijkstra dari PT. Y ke PT. Z

\begin{tabular}{c|c|c|c|c|c|c}
\hline Node & $\mathbf{Y}$ & $\mathbf{D}$ & $\mathbf{E}$ & $\mathbf{F}$ & $\mathbf{G}$ & $\mathbf{Z}$ \\
\hline $\mathbf{Y}$ & $0 \mathrm{Y}$ & $2,9 \mathrm{Y}$ & $3,4 \mathrm{Y}$ & $\infty$ & $\infty$ & $\infty$ \\
\hline $\mathbf{D}$ & & $2,9 \mathrm{Y}$ & $3,4 \mathrm{Y}$ & $7,2 \mathrm{D}$ & $\infty$ & $\infty$ \\
\hline $\mathbf{E}$ & & & $3,4 \mathrm{Y}$ & $7,2 \mathrm{D}$ & $8 \mathrm{E}$ & $\infty$ \\
\hline $\mathbf{F}$ & & & & $7,2 \mathrm{D}$ & $8 \mathrm{E}$ & $\infty$ \\
\hline $\mathbf{G}$ & & & & & $8 \mathrm{E}$ & $10,7 \mathrm{G}$ \\
\hline $\mathbf{Z}$ & & & & & & $10,7 \mathrm{G}$ \\
\hline
\end{tabular}

Setelah dilakukan pembuktian, selanjutnya dilanjutkan pemetaan jalur distribusi yang optimal dari PT. X ke PT. Y dan PT. Z terlihat pada gambar 6 sebagai berikut.

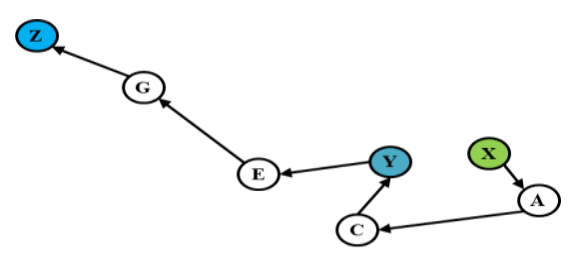

Gambar 6. Pemetaan jalur distribusi optimal dari PT. X ke PT. Y \& PT. Z

\section{KESIMPULAN}

Dari penelitian dan hasil implementasi algoritma Dijkstra berdasarkan lintasannya maka dapat diambil kesimpulan bahwa jalur distribusi yang optimal ialah dari PT. X ke PT. Y melalui Polda Jawa Barat kemudian Carefour dengan jarak 12,3 Km. Kemudian dilanjutkan dengan jalur distribusi dari PT. Y ke PT. Z melalui Simpang Lima Kemudian Vie Hotel Westhoff dengan jarak 10,7 Km. Sehingga total jarak yang harus ditempuh untuk mendistribusikan barang dengan optimal dari PT. X ke PT. Y kemudian PT. Z adalah 23 Km. 


\section{DAFTAR PUSTAKA}

Agustinus, R. (2018). Optimasi Masalah Transportasi Stokastik. http://repositori.usu.ac.id

Ardana, D., \& Saputra, R. (2016). Penerapan Algoritma Dijkstra pada Aplikasi Pencarian Rute Bus Trans Semarang. In Seminar Nasional Ilmu Komputer.

Ferdiansyah, \& Rizal, A. (2013). Penerapan Algoritma Dijkstra untuk Menentukan Rute Terpendek Pembacaan Water Meter Induk PDAM Tirta Kerta Raharja Kabupaten Tangerang. In Jurnal TICOM (Vol. 2, Issue 1).

Halda, R., Ranius, A. Y., Kom, S., Syaputra, H., Kom, M., Universitas, M., Darma, B., \& Universitas, D. (2016). Implementasi Algoritma Dijkstra Untuk Menentukan Jalur Terpendek Rumah Sakit Di Kota Palembang.

Harahap, M. K., \& Khairina, N. (2017). Pencarian Jalur Terpendek dengan Algoritma Dijkstra. SinkrOn, 2(2), 18. https://doi.org/10.33395/sinkron.v2i2.61

Ismet. (2014). Pengertian Sub-kontraktor Pada Proyek. Retrieved June 7, 2021, from http://projectmedias.blogspot.com/2014/01/pengertian-subkontraktor-pada-proyek.html

Kholik, A., Wahyudi, E. E., Devianto, K., \& Sholihah, N. (2018). Sistem Rekomendasi Berbasis Genetic Algorithm: Studi Kasus Pembelian Komponen Komputer dan Aksesorisnya. Seminar Nasional Aplikasi Teknologi Informasi (SNATi) 2018, 30-34.

Mahdia, F. (2013). PEMANFAATAN GOOGLE MAPS API UNTUK PEMBANGUNAN SISTEM INFORMASI MANAJEMEN BANTUAN LOGISTIK PASCA BENCANA ALAM BERBASIS MOBILE WEB. Retrieved June 7, 2021, from https://media.neliti.com

Nurrizky, M. F., Dwiagnes, S., \& Anggraeni, N. F. (2020). Pencarian Rute Terpendek Pada Distribusi Raw Material Metode Djikstra Di PT. SHP. Jurnal Teknik: Media Pengembangan Ilmu Dan Aplikasi Teknik, 34. https://doi.org/10.26874/jt.vol19no01.141

Wijayanti, S., Prihandono, B., \& Kusnandar, D. (2015). Algoritma Dijkstra Untuk Mencari Lintasan Terpendek Dan. 04(3), 243-250. 